\title{
A Regeneration and Agrobacterium-mediated Transformation System for Genetically Diverse Chrysanthemum Cultivars
}

\author{
John M. Sherman, James W. Moyer, and Margaret E. Daub ${ }^{1}$ \\ Department of Plant Pathology, North Carolina State University, Raleigh, NC 27695-7616
}

AdDitional InDEx worns. Dendranthema grandiflora, plant cell culture, tissue culture, floral crop biotechnology

\begin{abstract}
An efficient, high-frequency regeneration and Agrobacterium-mediated transformation system was developed allowing the genetic engineering of three chrysanthemum (Dendranthema grandiflora Tzvelev) cultivars: the formerly recalcitrant and economically important cut-flower mum 'Polaris' and two potted mums, 'Hekla' and 'Iridon'. The regeneration protocol used leaf explants on a sequence of media with four hormone regimes. Explants were first cultured on an embryogenesis-type medium containing a high concentration of 2,4-D, which promoted callus formation. Shoot primordia were induced by culture on medium lacking 2,4-D, followed by shoot elongation on a high-cytokinin plus gibberellic acid medium. Finally, elongated shoots were rooted on a low-auxin rooting medium. Transformed plants of the three cultivars were obtained following co-culture of leaf explants with $A$. tumefaciens strain EHA105 harboring the plasmid pBI121 containing genes for neomycin phosphotransferase II (NPTII) and $\beta$-glucuronidase (GUS). Stable transformation of the three cultivars was verified via GUS assays and Southern analysis.
\end{abstract}

The development of genetic transformation systems for chrysanthemum (Dendranthema grandiflora) offers the possibility of quickly placing agronomically useful traits into this crop, e.g., insect and pathogen resistance, increased vase life, and flower color modifications (Daub et al., 1997; Robinson and Firoozabady, 1993). Traditional breeding for disease and insect resistances is hampered by incompatibility barriers and high ploidy levels. Furthermore, polygenic sexual crosses can disrupt the delicate balance of uniform growth and synchronous flowering that makes specific cultivars desirable (Dons et al., 1991). The ability of recombinant DNA technology to yield desirable changes in cultivars without disturbing important ornamental traits has resulted in efforts to develop efficient transformation systems for chrysanthemum that are applicable to many cultivars.

There are an increasing number of reports of successful chrysanthemum transformation (Courtney-Gutterson et al., 1993; Ledger et al., 1991; Pavingerova et al., 1994; Renou et al., 1993; Seiichi et al., 1995; Urban et al., 1994). However, the utility of these transformation systems is reduced by low transformation efficiencies and high levels of cultivar specificity. Transformation protocols adapted to easily transformable cultivars often fail for less responsive ones (Ledger et al., 1991; Pavingerova et al., 1994; Renou et al., 1993, Seiichi et al, 1995; Urban et al., 1994). To date, only Yepes et al. (1995) have reported transformation of multiple cultivars using a biolistic procedure.

In this study, we describe a high-frequency Agrobacteriummediated transformation system successful for three distinct chrysanthemum cultivars. Using a sequential series of four growth regulator regimes has resulted in the ability to transform the formerly recalcitrant 'Polaris' and two potted mums, 'Iridon' and 'Hekla'. Unlike other chrysanthemum transformation studies, we

Received for publication 23 Dec. 1996. Accepted for publication 17 Oct. 1997. We thank Stanton Gelvin for the gift of Agrobacterium tumefaciens strain EHA105. This work was funded by grants from the American Floral Endowment and the North Carolina Biotechnology Center. Mention of a trademark, proprietary product, or vendor does not imply its approval to the exclusion of other products or vendors that also may be suitable. The cost of publishing this paper was defrayed in part by the payment of page charges. Under postal regulations, this paper therefore must be hereby marked advertisement solely to indicate this fact.

To whom reprint requests should be addressed. focused on genetic engineering of a recalcitrant cultivar and found that the protocol devised also works for easily transformable ones. Such a system, allowing transformation of genetically diverse cultivars, is necessary for the successful deployment of virus resistance genes, e.g., against tomato spotted wilt virus (TSWV), a current major threat to chrysanthemum production.

\section{Materials and Methods}

Plant material. 'Polaris' (a cut-flower mum), 'Iridon', and 'Hekla' (potted mums) plants were grown in a greenhouse in 15$\mathrm{cm}$ pots in 1 soil : 1 metromix. Plants were fertilized monthly with Peters professional water-soluble fertilizer (20-10-20, ScottsSierra Horticultural Products Co., Marysville, Ohio) and were provided with continuous supplemental fluorescent illumination that maintained them in a vegetative state. Plants were vegetatively propagated at monthly intervals by excising cuttings (four to five nodes per cutting) from the plants, removing the bottom two sets of leaves, and transplanting the cuttings into pots containing the above soil mix. Average greenhouse temperatures ranged from $\approx 18$ to $30^{\circ} \mathrm{C}$ depending on the time of day and season.

EXPLANT PREPARATION. Explants were prepared from the top four fully expanded leaves of plants up to 3 months old. The leaves were harvested and surface-sterilized in $0.13 \%$ sodium hypochlorite plus $0.05 \%$ sodium dodecyl sulfate (SDS) for $10 \mathrm{~min}$, followed by three rinses in sterile distilled water. Leaf disk explants $(12 \mathrm{~mm}$ in diameter) were placed with the adaxial surface in contact with medium (described below), and were transferred to fresh medium every 2 weeks. Cultures were placed in a growth chamber at $25^{\circ} \mathrm{C}$ with a 16-h day/8-h night using fluorescent lamps at 20 to 55 $\mu \mathrm{mol} \cdot \mathrm{m}^{-2} \cdot \mathrm{s}^{-1}$. Yellow plexiglass filters were placed over plates of 'Polaris' explants, with filtered light intensities of 15 to 20 $\mathrm{mmol} \cdot \mathrm{m}^{-2} \cdot \mathrm{s}^{-1}$ (Urban et al., 1994).

Plant regeneration. All media consisted of basal Murashige and Skoog (MS) medium (Murashige and Skoog, 1962) containing $3 \%$ sucrose and solidified with $0.8 \% \mathrm{w} / \mathrm{v}$ Bacto-agar (Difco Laboratories). Medium $\mathrm{pH}$ was adjusted to 5.7 before autoclaving. Growth regulator solutions were filter-sterilized $(0.45 \mathrm{~mm})$ and added after medium sterilization. All experiments used 100-mm petri dishes with $\approx 25 \mathrm{~mL}$ medium per dish. 
The effects of 2,4-dichlorophenoxyacetic acid (2,4-D) concentration and incubation period were tested by using 'Polaris' explants cultured for 7, 14, and $21 \mathrm{~d}$ on Mum B medium (May and Trigiano, 1991, Urban et al., 1994) [MS medium, $2.0 \mathrm{mg} \cdot \mathrm{L}^{-1}$ indoleacetic acid (IAA), and $0.23 \mathrm{mg} \cdot \mathrm{L}^{-1}$ benzyladenine (BA)] plus $2,4-\mathrm{D}$ at $0,0.25,0.5,0.75$, and $1.0 \mathrm{mg} \cdot \mathrm{L}^{-1}$, followed by transfer to Mum B medium without 2,4-D. Eight weeks after initial culture, the number of explants responding and the number of shoots produced per explant were recorded.

Based on the results of the 2,4-D study, a single medium consisting of Mum B plus $0.5 \mathrm{mg} \cdot \mathrm{L}^{-1}$ 2,4-D (Mum 2,4-D) was selected for the initial stage. Leaf explants were placed on Mum 2,4-D medium for 2 weeks, followed by transfer to Mum B (no 2,4D) for the development of shoot primordia. When shoot primordia developed ( 2 to 4 weeks depending on the cultivar), callus pieces plus primordia were excised from the original explants and placed on shoot elongation medium (Mum EL) (Earle and Langhans, 1974), consisting of MS medium plus $2.0 \mathrm{mg} \cdot \mathrm{L}^{-1}$ kinetin (Kin), $0.02 \mathrm{mg} \cdot \mathrm{L}^{-1}$ naphthaleneacetic acid (NAA), and $10 \mathrm{mg} \cdot \mathrm{L}^{-1}$ gibberellic acid $\left(\mathrm{GA}_{3}\right)$. After 4 weeks on Mum EL, the number of shoots produced and the regeneration frequency for each cultivar were determined. A fourth medium (1/4 strength MS medium plus 0.1 $\left.\mathrm{mg} \cdot \mathrm{L}^{-1} \mathrm{NAA}\right)$ was used for rooting shoots.

Agrobacterium CULTURE. Agrobacterium tumefaciens strain EHA 105, a disarmed version of the wide host range strain A281, was cultured in liquid yeast extract peptone (YEP) medium (An et al., 1988) with $50 \mathrm{mg} \cdot \mathrm{L}^{-1}$ rifampicin. The plant transformation vector pBI121 (Clontech Laboratories, Inc., Palo Alto, Calif.) containing neomycin phosphotransferase II (nptII) and $\beta$-glucuronidase $(g u s)$ genes was mobilized into EHA105 via a freezethaw procedure (An et al., 1988). Bacteria containing this plasmid were selected and maintained on medium amended with $50 \mathrm{mg} \cdot \mathrm{L}^{-1}$ kanamycin and were stored in $50 \%$ glycerol at $-80^{\circ} \mathrm{C}$.

Plant transformation. Transformation of the three cultivars was accomplished using the four step plant regeneration series described previously. Leaf disks were exposed to A. tumefaciens by swirling in an overnight culture (O.D.600 $\approx 2.2$ ) diluted $1: 50$ in liquid MS medium. Disks were swirled 10 to $15 \mathrm{~s}$, blotted on sterile paper towels to remove excess bacteria, and placed (five explants per plate) on Mum 2,4-D medium. After $5 \mathrm{~d}$, co-cultivation was terminated and transformed cells were selected by placing the explants on fresh Mum 2,4-D medium containing $500 \mathrm{mg} \cdot \mathrm{L}^{-1}$ carbenicillin and $50 \mathrm{mg} \cdot \mathrm{L}^{-1}$ paromomycin (Sigma Co., St. Louis). Explants were regularly observed for callus proliferation (4 to 6 weeks, depending on the cultivar) and then moved to Mum B medium, which lacked 2,4-D but contained carbenicillin and paromomycin. Explants were maintained on this medium until developing shoot primordia were observed, at which time callus pieces containing primordia were excised from the dying explants and placed on Mum EL medium plus carbenicillin and paromomycin. Shoots were allowed to develop and elongate on Mum EL medium ( 4 to 6 weeks) before excision and then were placed on rooting medium containing carbenicillin and paromomycin. Following rooting on selective medium, putative transformed plants were established in planting medium in the greenhouse. No shoots were recovered from control explants plated on medium with $50 \mathrm{mg} \cdot \mathrm{L}^{-1}$ paromomycin.

DNA EXTRACTION. Leaf tissue was ground in liquid $\mathrm{N}_{2}$ and mixed $(0.2 \mathrm{~g}$ fresh mass per $\mathrm{mL})$ with extraction buffer $[100 \mathrm{~mm}$ Tris- $\mathrm{OH}$, $100 \mathrm{~mm} \mathrm{Na} \mathrm{NaDTA}_{2}$, $700 \mathrm{mM} \mathrm{NaCl}, 1.0 \%$ hexadecyltrimethylammonium bromide (CTAB), $2.5 \% \beta$-mercaptoethanol, and $3.9 \mathrm{mg} \cdot \mathrm{L}^{-1} \mathrm{NaSO}_{3}$ ] (McGarvey and Kaper, 1991). Following suspension of the leaf powders, $N$-lauryl-sarcosine (SLS) was added to a final concentration of $1.0 \%$, and samples were incubated for $1 \mathrm{~h}$ at $65^{\circ} \mathrm{C}$, cooled to room temperature, and extracted with an equal volume of chloroform $\left(\mathrm{CHCl}_{3}\right)$. Following centrifugation at $8,160 g_{\mathrm{n}}$ for $10 \mathrm{~min}$, nucleic acids were precipitated from the supernatants with an equal volume of isopropanol. Nucleic acids were pelleted by centrifugation, washed with $70 \%$ ethanol, and resuspended in high-salt Tris-EDTA buffer $(10 \mathrm{~mm}$ Tris-Cl, $1 \mathrm{~mm}$ $\mathrm{Na}_{2}$ EDTA, and $1 \mathrm{M} \mathrm{NaCl}, \mathrm{pH} 8.0$ ) for polysaccharide removal and with $10 \mathrm{mg} \cdot \mathrm{L}^{-1}$ RNase A for RNA digestion (Fang et al., 1992). Following RNase treatment for $2 \mathrm{~h}$ at room temperature, samples were extracted with an equal volume of 1 phenol : $1 \mathrm{CHCl}_{3}$ followed by one extraction with $\mathrm{CHCl}_{3}$. DNA was precipitated with 2 volumes of $95 \%$ ethanol and 0.1 volumes of $3 \mathrm{M} \mathrm{NaOAc}$, pelleted by centrifugation, washed with $70 \%$ ethanol, and resuspended in TE buffer before use in polymerase chain reaction (PCR) and Southern blot analyses. DNA concentrations were quantified using a spectrophotometer.

PCr anal,ysis. Plants that regenerated and rooted on paromomycin-containing medium were initially screened for the presence of the nptII gene by PCR. Genomic DNA $(0.5 \mathrm{mg})$ was PCR-amplified using two primers specific to the nptII gene of pBI 121. Primer 1 (5'-CCC TGA ATG AACTGC AGG AC-3') and primer 2 (5'-GAA CTC GTC AAG AAG GCG AT-3') produce a 602-bp fragment representing a portion of the nptII gene. DNA extracted from nontransformed plants $(0.5 \mathrm{mg})$ and purified $\mathrm{pBI} 121$ $(0.1 \mathrm{mg})$ were used as negative and positive controls, respectively. PCR amplification was conducted in $100-\mathrm{mL}$ volumes with a denaturation step at $94^{\circ} \mathrm{C}$ for $1 \mathrm{~min}$, an annealing step at $55^{\circ} \mathrm{C}$ for $1 \mathrm{~min}$, and an extension step at $72^{\circ} \mathrm{C}$ for $2 \mathrm{~min}$, for a total of 30 cycles. After amplification was complete, $20 \mathrm{~mL}$ of each sample was electrophoresed through a $1 \times$ TBE $(0.089 \mathrm{M}$ Tris-OH, $0.089 \mathrm{M}$ boric acid, and $0.002 \mathrm{M}$ NaEDTA), $0.8 \%$ agarose gel.

Southern ANALysis. Genomic DNA isolated from PCR-positive plants was digested with $X b a I$, which cuts pBI121 at a single site outside the 3 ' end of the nptII sequence. Samples $(30 \mathrm{mg})$ were separated by electrophoresis through a $1 \times \mathrm{TBE}, 0.8 \%$ agarose gel and transferred to $0.45-\mathrm{mm}$ filters (Magnagraph; Micron Separa-

Table 1. Effect of 2,4-D concentration and exposure time on shoot regeneration of 'Polaris' chrysanthemum 6 weeks after culture initiation on Mum B medium.

\begin{tabular}{lccc}
\hline $\begin{array}{l}\text { Time on Mum B } \\
\text { medium }\end{array}$ & $\begin{array}{c}\text { Explants } \\
\text { producing shoots }\end{array}$ & $\begin{array}{c}\text { Avg. no. } \\
\text { of shoots } \\
\text { per explant }\end{array}$ \\
\hline 0 & $(\mathrm{~d})$ & $(\%)$ & $0.23 \mathrm{gh}$ \\
& 7 & $17 \mathrm{fg}^{2}$ & $0.13 \mathrm{~h}$ \\
0.25 & 14 & $7 \mathrm{~g}$ & $0.35 \mathrm{fgh}$ \\
& 21 & $21 \mathrm{efg}$ & $0.47 \mathrm{fgh}$ \\
& 7 & $80 \mathrm{bc}$ & $1.97 \mathrm{~b}$ \\
0.50 & 14 & $45 \mathrm{~d}$ & $0.90 \mathrm{def}$ \\
& 21 & $94 \mathrm{ab}$ & $2.61 \mathrm{a}$ \\
0.75 & 7 & $97 \mathrm{a}$ & $2.10 \mathrm{ab}$ \\
& 14 & $68 \mathrm{c}$ & $1.08 \mathrm{cde}$ \\
& 21 & $32 \mathrm{de}$ & $0.68 \mathrm{efgh}$ \\
1.0 & 7 & $76 \mathrm{c}$ & $1.55 \mathrm{bc}$ \\
& 14 & $23 \mathrm{ef}$ & $0.23 \mathrm{gh}$ \\
& 21 & $69 \mathrm{c}$ & $1.28 \mathrm{dc}$ \\
& 7 & $79 \mathrm{c}$ & $1.62 \mathrm{bc}$ \\
& 14 & $30 \mathrm{ef}$ & $0.70 \mathrm{efg}$ \\
\hline
\end{tabular}

${ }_{\mathrm{z}}$ Numbers within columns followed by the same letter are not significantly different according to Fisher's L.SD test $(P=0.05)$. Data shown are the means from three replications and 10 explants per replication. 
Table 2. Transformation of 'Polaris', 'Hekla', and 'Iridon' chrysanthemum plants with Agrobacterium strain EHA105 containing plasmid pBI121. ${ }^{2}$

\begin{tabular}{|c|c|c|c|c|c|c|c|}
\hline Cultivar & $\begin{array}{c}\text { Leaf disk } \\
\text { explants } \\
\text { (no.) }\end{array}$ & $\begin{array}{c}\text { Leaf disks } \\
\text { with shoots } \\
\quad(\%)\end{array}$ & $\begin{array}{c}\text { Total } \\
\text { shoots } \\
\text { (no.) }\end{array}$ & . & $\begin{array}{c}\text { Shoots } \\
\text { rooted } \\
\text { (no.) }\end{array}$ & $\begin{array}{l}\text { Avg. rooted } \\
\text { shoots/explant } \\
\text { (no.) }\end{array}$ & $\begin{array}{c}\text { PCR-positive } \\
(\%)\end{array}$ \\
\hline Polaris & 80 & 91 & 146 & & 134 & 1.7 & 96 \\
\hline Hekla & 30 & 73 & 142 & & 123 & 4.1 & 75 \\
\hline Iridon & 22 & 82 & 49 & & 11 & 0.5 & 50 \\
\hline
\end{tabular}

${ }^{\mathrm{Z}}$ Data shown are percentages calculated from the total number of explants and rooted shoots from at least four replications with five explants per replication.

tions, Inc., Westborough, Mass.) by capillary blotting. The resultant blots were hybridized to a probe generated by PCR using primers 1 and 2 and purified pBI121 as a template. The PCR product was labeled with ${ }^{32} \mathrm{P}$ using an oligollabeling kit (Pharmacia Biotech, Inc., Piscataway, N.J.). High stringency washes (O.1× $\mathrm{SSC}, 1.0 \% \mathrm{SDS}, 65^{\circ} \mathrm{C}$ ) were performed before placing the blots in a phosphoscreen (Molecular Dynamics, Sunnyvale, Calif.).

GUS ASSAYS. GUS fluorometric assays were performed on PCRpositive plants that had been established in the greenhouse for at least 2 months. GUS activity was assayed by measuring the conversion of 4-methylumbelliferyl $\beta$-D-glucuronide (MUG) to 4-methylumbelliferone (MU) by leaf extracts as described by Jefferson (1987). Leaf extracts were prepared by grinding $500 \mathrm{mg}$ of young leaf tissue in $500 \mathrm{~mL}$ of GUS extraction buffer (Jefferson, 1987), and reactions were terminated at $0,30,60,90$, and $120 \mathrm{~min}$. The amount of protein present in reaction mixtures was determined by the Bradford (1976) method using a kit from BioRad Laboratories (Hercules, Calif.). No GUS activity was detected in nontransformed plants of any of the three cultivars.

\section{Results}

Plant Regeneration. In preliminary experiments, using tobacco suspension cell feeder layers significantly increased the number of shoots regenerated from 'Polaris' explants using a regeneration procedure described by Urban et al. (1994). It was subsequently determined that the 2,4-D in the tobacco suspension culture medium, and not the tobacco cells, was responsible for the stimulatory effect. We therefore investigated the effect of 2,4-D on 'Polaris' regeneration. 'Polaris' leaf-disk explants cultured on Mum B regeneration medium augmented with different 2,4-D concentrations exhibited callus formation at the cut edge, which gave rise to shoot primordia when explants were moved to Mum $\mathrm{B}$ medium lacking 2,4-D. Initial culture of explants on 2,4-D levels from 0.25 to $1.0 \mathrm{mg} \cdot \mathrm{L}^{-1}$ for 7,14 , or $21 \mathrm{~d}$ resulted in a greater number of explants producing shoots and more shoots per explant than culture on medium lacking 2,4-D (Table 1). In general, shoot regeneration increased when exposure times on Mum 2,4-D were lengthened from 7 to $14 \mathrm{~d}$, but decreased at $21 \mathrm{~d}$. The highest percentage of explants responding and highest number of shoots produced per explant occurred with initial culture on Mum B containing $0.5 \mathrm{mg} \cdot \mathrm{L}^{-1} 2,4-\mathrm{D}$ with an exposure time of 7 or $14 \mathrm{~d}$; thus, Mum 2,4-D medium (Mum B plus $0.5 \mathrm{mg} \cdot \mathrm{L}^{-1} 2,4-\mathrm{D}$ ) and an exposure time of $14 \mathrm{~d}$ was chosen as the initial medium for 'Polaris' regeneration.

Culture of 'Polaris' leaf explants for $14 \mathrm{~d}$ on Mum 2,4-D followed by transfer to Mum B lacking 2,4-D resulted in shoot primordia development. However, it was observed that only a few of the primordia that emerged would elongate into shoots. To increase the frequency of shoot formation further, callus pieces containing developing primordia were removed from explants and cultured on Mum EL. Transfer of callus and shoot primordia developed on Mum 2,4-D and Mum B media to Mum EL medium caused $96 \%$ of Polaris explants to produce shoots, and a much higher number of shoots produced per explant (8.2 vs. 2.1) than with Mum 2,4-D and Mum B alone.

The three step regime was also shown to generate high numbers of regenerated shoots from explants of 'Hekla' and 'Iridon'. Of the 80 'Hekla' and 130 'Iridon' explants tested, 91\% and 94\%, respectively, produced shoots with an average of 17.2 and 13.7 shoots per explant, respectively. These regeneration frequencies are significantly greater than those previously obtained for these cultivars ( 0.9 to 1.0 shoots per explant) when explants were cultured continuously on Mum B medium alone (Urban et al., 1994).

Plant transformation. By coupling the above regeneration regime with Agrobacterium co-culture and regeneration on paromomycin-containing media, we were able to transform the formerly recalcitrant 'Polaris' in addition to the more regeneration-amenable 'Iridon' and 'Hekla'. The only differences in cultivar requirements were that 'Polaris' culture required filtering light through yellow plexiglass filters, and that regeneration of transformed 'Iridon' and 'Hekla' plants was quicker than 'Polaris'. Transformation of all cultivars used a 5-d co-culture period and 3 weeks for rooting. For the other stages of transformation-transformed callus initiation and selection (on Mum 2,4-D plus paromomycin), induction of shoot primordia (on Mum B plus paromomycin), and elongation and multiplication of shoots (on Mum EL plus paromomycin)_- 'Hekla' and 'Iridon' required 4, 2, and 4 weeks, respectively, whereas 'Polaris' required 6, 4, and 6 weeks, respectively. Putatively transformed shoots developed and

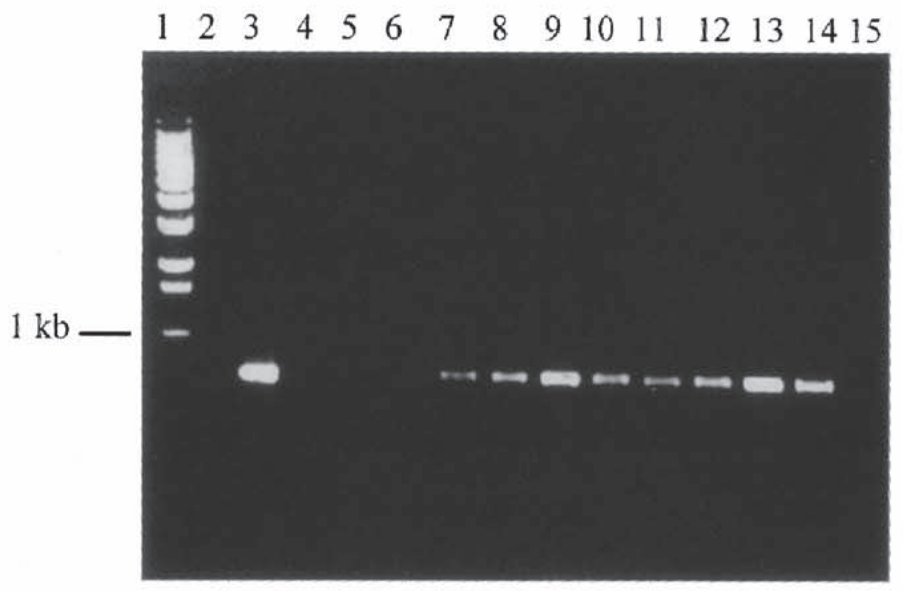

Fig 1. Polymerase chain reaction (PCR) analysis of chrysanthemum transformants. Lane 1: 1-kb ladder. Lane 2: no DNA control. Lane 3: purified pBI121. Lanes 4 6: DNA from nontransformed 'Polaris', 'Hekla', and 'Iridon' plants, respectively. Lanes 7-15: DNA from putatively transformed plants, which regenerated and rooted in the presence of $50 \mathrm{mg} \cdot \mathrm{L}^{-1}$ paromomycin. Lanes 7-9: 'Polaris'. Lanes 10-12, 'Hekla'. Lanes 13-15: 'Iridon'. Not all plants that survived selection on paromomycin were stably transformed (e.g., lane 15). 


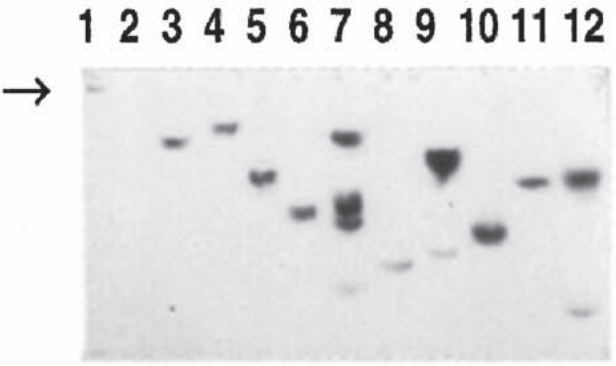

Fig. 2. Southern blot hybridization analysis of transformed 'Polaris', 'Iridon', and 'Hekla' chrysanthemum. Lane 1: purified pBI121 digested with XbaI; arrow indicates the 13-kb plasmid band. Lane 2: DNA from nontransformed 'Polaris' plant. Lanes 3-6: DNA from PCR-positive transformed 'Polaris' plants. Lanes 79: DNA from PCR-positive 'Iridon' plants. Lanes 10-12: DNA from PCRpositive 'Hekla' plants.

successfully produced roots on rooting medium with $50 \mathrm{mg} \cdot \mathrm{L}^{-1}$ paromomycin. The percentage of explants producing shoots and the average number of rooted shoots per explant are provided in Table 2. Definite cultivar differences in transformation frequencies are evident; 'Hekla' was the most successfully transformed genotype, followed by 'Polaris' and 'Iridon'.

CONFIRMATION OF TRANSFORMATION. Initial confirmation of transformation was done via PCR analysis of plants that had rooted in the presence of $50 \mathrm{mg} \cdot \mathrm{L}^{-1}$ paromomycin and had been grown in pots in the greenhouse for 2 months. Amplification of genomic DNA containing the $n p t I I$ gene with the primers listed resulted in an $\approx 600$-bp product in $96 \%, 75 \%$, and $50 \%$ of regenerated 'Polaris', 'Hekla', and 'Iridon' plants, respectively (Fig. 1, Table 2). These amplification products co-migrated with product amplified from pBI121. Nontransformed plant DNA yielded no product.

Southern analysis was performed to confirm that the presence of the nptII gene in PCR-positive plants was due to the stable integration of the T-DNA into the plant genome (Fig. 2). Digestion of pBI121 plasmid DNA with XbaI cuts the plasmid at a single site outside the 3 ' coding region of the nptII gene. Presence of contaminating plasmid in the tissues can be detected by the presence of a single 13-kb band (lane 1, arrow). DNA from PCR-positive plants contained one or more bands of differing sizes, indicating that single and multiple-copy integration of the nptII gene into the genome had occurred. Nontransformed control plants produced no signal.

Transgene expression was confirmed by assaying GUS activity in randomly selected PCR-positive plants. Detectable GUS activity levels of five PCR-positive plants of each cultivar are shown in Fig. 3. Overall, 100\%, 84\%, and 75\%, respectively, of the PCRpositive 'Polaris', 'Hekla', and 'Iridon' plants expressed detectable levels of GUS activity. No GUS activity was detected in nontransformed and vector transformed controls.

\section{Discussion}

We have developed a regeneration protocol, which, when combined with the use of Agrobacterium, allows high frequency recovery of transformed plants of three distinct chrysanthemum cultivars. The protocol was developed using the white, cut-flower 'Polaris'. 'Polaris' is an economically important cultivar that has been the subject of previous transformation studies (Urban et al, 1994; Yepes, et al. 1995), but, to date, stably transformed plants have not been recovered from this cultivar. Rather than concentrate on more regeneration-amenable cultivars, we chose to improve the regeneration of 'Polaris' to a level allowing transforma- tion. We then demonstrated that the regeneration and transformation procedure developed for this recalcitrant cultivar is applicable to two other cultivars-Iridon, a yellow potted-mum, and Hekla, a single; daisy-type white and yellow potted mum.

The development of the shoot regeneration and transformation protocol is a significant advancement, as current regeneration protocols for chrysanthemum have been shown in almost all cases to be highly cultivar dependent. Studies on chrysanthemum shoot regeneration from excised ray florets (Malure et al., 1991), stem explants (Kaul et al., 1990), protoplasts (Sauvadet et al., 1990), and somatic embryos (May and Trigiano, 1991) found wide ranges in shoot regeneration capacities among different cultivars. Cultivar specificity in regeneration requirements is a major concern for transformation systems where the added manipulations (e.g., Agrobacterium inoculation or tissue bombardment and the application of selection pressure) usually lowers the regeneration capacities of cultivars. As a result, most chrysanthemum transformation studies have concentrated on a single, highly regenerationamenable cultivar. Ledger et al. (1991), Pavingerova et al. (1994), Renou et al. (1993), Seiichi et al. (1995), and Urban et al. (1994) tested the regeneration capacities of several cultivars before choosing the most responsive genotype for transformation studies. To date, only Yepes et al. (1995) obtained transformed plants of multiple (four) cultivars using a single protocol. However, they relied on particle bombardment for transformation, a system that has the disadvantage of often producing high levels of transient expression rather than stable integration of transgenes (Potrykus, 1990)

We found that successful regeneration of transformed 'Polaris' plants required transfer of the leaf disk explants on MS medium with a series of hormone regimes that separately induced callus formation, shoot primordia, shoot elongation, and rooting. The initial production of callus leading to subsequent shoot primordia initiation was greatly enhanced by initial culture of explants on Mum B medium containing $0.5 \mathrm{mg} \cdot \mathrm{L}^{-1} 2,4-\mathrm{D}$ with an exposure time of $14 \mathrm{~d}$. Other reports on chrysanthemum regeneration have also demonstrated a positive effect of 2,4-D on regeneration (Bhattacharya et al., 1990; Fujii and Shimizu, 1990), although both studies found that exposure to high levels of $2,4-\mathrm{D}\left(2 \mathrm{mg} \cdot \mathrm{L}^{-1}\right)$ for extended periods inhibited shoot formation. We saw a similar

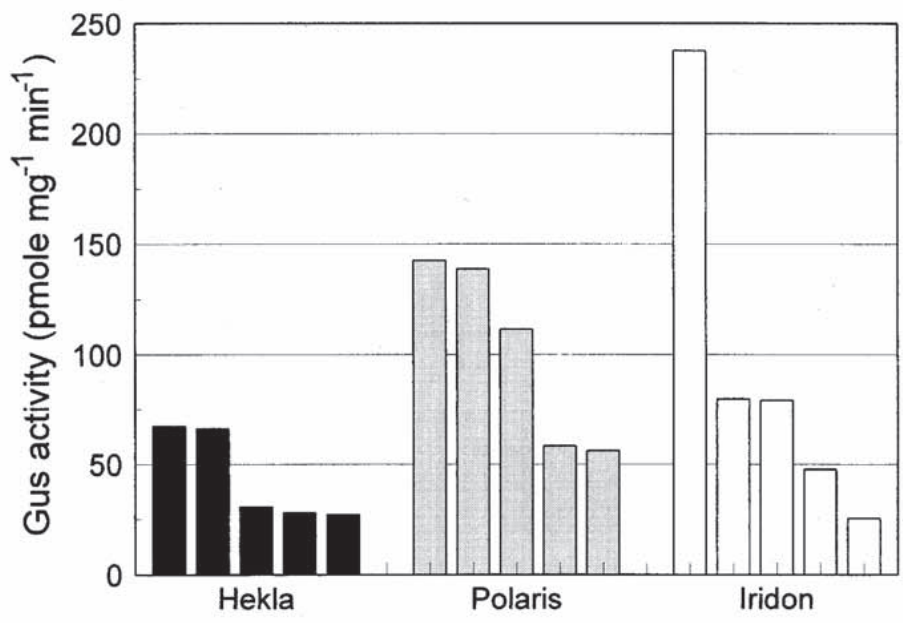

Fig. 3. GUS activities of five randomly selected PCR-positive 'Polaris', 'Hekla', and 'Iridon' chrysanthemum plants transformed with pBI121. Bars represent the mean levels of GUS activity per milligram protein of three replications per individual transformed plant of the specified cultivars. Standard errors for each mean ranged from \pm 0.9 to \pm 13 . 
effect in our study and further found that production of shoot primordia from explant callus required transfer of explants to medium lacking 2,4-D.

Observations of 'Polaris' explants indicated that shoot primordia that formed after movement of explants from Mum 2,4-D to Mum B medium often would not elongate into shoots. By transferring primordia to a medium containing a high cytokinin to auxin ratio plus $\mathrm{GA}_{3}$, the shoot primordia could be induced to develop further, thus increasing regeneration frequencies. We attribute the increased shoot regeneration to the stimulatory effects of $\mathrm{GA}_{3}$ on shoot elongation and proliferation.

Unlike the present system, most published chrysanthemum transformation systems have used continuous exposure to a high cytokinin and low auxin regeneration medium to induce organogenesis (Courtney-Gutterson et al., 1993, Ledger et al., 1991; Renou et al., 1993, Seiichi et al., 1995). Pavingerova et al. (1994) were able to transform chrysanthemum cultivars using a somatic embryogenesis plant regeneration scheme. Pavingerova et al. (1994) and May and Trigiano (1991) hypothesized that somatic embryogenesis would ensure the single-cell origin of transformed plants and decrease the possibility of chimeras. While the first two steps of our regeneration and transformation system use high auxin and low cytokinin media typical of embryogenic regeneration systems, we never observed embryo formation. May and Trigiano (1991) found that high sucrose levels ( $>9 \%$ ) were necessary for embryo formation and that organogenesis was stimulated on medium with $3 \%$ sucrose (the level used herein). Based on GUS and PCR assays of different leaves of our transformed plants, we found no indications of chimeric transformants, and we hypothesize that using the high auxin to cytokinin ratio growth regulator regime may have stimulated single cell differentiation.

By successfully coupling our four-step plant regeneration procedure with Agrobacterium inoculation, we obtained higher transformation frequencies than previously reported for chrysanthemum. As not all studies have reported on the numbers of plants confirmed as transformed by Southern or PCR analysis, transformation frequencies are compared based on the numbers of plants recovered following culture on selective media. These frequencies ranged from a low of $<0.1$ plants per explant for 'Moneymaker' to a high of 0.6 plants per explant for ' 1581' (Courtney-Gutterson et al., 1993; Pavingerova et al., 1994; Renou et al., 1993; Seiichi et al., 1995; Urban et al., 1994). Using our protocol, we increased the transformation frequency of 'Iridon' from 0.1 (Urban et al., 1994) to 0.5 plants per explant. Our highest frequencies were for 'Hekla' and 'Polaris' (4.1 and 1.7 plants per explant, respectively), which compares favorably to those of Yepes et al. (1995) (2.5 to 4.6 plants per explant for four cultivars), using a biolistic procedure. Yepes et al. (1995), however, were unable to transform 'Polaris', citing low regeneration response as a problem.

In our system, successful transformation of all three cultivars also required substituting the selective agent paromomycin for the more commonly used kanamycin. Differences in the tolerances of mum cultivars to kanamycin have been reported (Lowe et al., 1993; Renou et al., 1993, Yepes et al., 1995). Some transformation systems (Ledger et al., 1991; Seiichi et al., 1995) used a very low level of kanamycin $\left(10 \mathrm{mg} \cdot \mathrm{L}^{-1}\right)$, a level that we found allowed regeneration of nontransformed 'Iridon' plants (Urban et al., 1994). Yepes et al. (1995) resorted to a delay in selection (10 d) followed by a stepwise increase in selection pressure. For similar reasons, Renou et al. (1993) found that hygromycin resistance was a better selectable marker for transformation of 'Pictor'. We also found that kanamycin had a detrimental effect on regeneration of transformed 'Polaris'; therefore, we used paromomycin for select- ing transformed shoots. This agent is considered to be less toxic to cells than kanamycin and allowed us to expose cultures to constant selection pressure during shoot regeneration and rooting and avoid the use of a delay in the application of selection, both of which decrease the chance of escapes. The only drawback discovered was that Phytagel (Sigma) could not be used as a gelling agent because paromomycin is insoluble in Phytagel-containing medium.

PCR analysis of plants that were regenerated and rooted in the presence of selection indicated that $96 \%, 75 \%$, and $50 \%$ of plants of 'Polaris', 'Hekla', and 'Iridon', respectively, contained the nptII gene. A lower proportion of PCR-positive plants obtained from 'Iridon' compared to other cultivars was also reported by Yepes et al. (1995). It is not clear why plants that are not stably transformed are recovered, as no shoots were ever recovered from control explants plated on selective medium. Transient expression of the nptII gene or cross-feeding may explain this observation. Southern analysis of PCR-positive plants demonstrated that the nptII transgene was incorporated stably and often in multiple sites within the plant genomes.

GUS assays on selected PCR-positive plants of the three cultivars indicated that the gus gene was expressed in $100 \%, 83 \%$, and $75 \%$, respectively, of transformed 'Polaris', 'Hekla', and 'Iridon' plants. GUS activity was found in levels comparable to other reports for transformed chrysanthemum (Pavingerova et al., 1994; Urban et al., 1994), but were $\approx 10$-fold less than for tobacco transformed with pBI121 (Daub et al., 1994). Low expression may be an important consideration for engineering virus resistance where gene expression levels are an important concern (Chasan, 1994). We are currently using this transformation protocol for engineering TSWV resistance into the economically important and highly TSWV-susceptible 'Polaris' (Sherman et al., 1996; Daub et al, 1997).

\section{Literature Cited}

An, G., P.R. Ebert, A. Mitra, and S.B. Ha. 1988. Binary vectors, p. A.3:119. In: S.B. Gelvin and R.A. Schilperoort (eds.). Plant molecular biology manual. Kluwer Academic Publ., Dordrecht.

Bhattacharya, P., S. Dey, N. Das, and B.C. Bhattacharya. 1990. Rapid mass propagation of Chrysanthemum morifolium by callus derived from stem and leaf explants. Plant Cell Rpt. 9:439-442.

Bradford, M.M. 1976. A rapid and sensitive method for detecting microgram quantities of protein utilizing the principle of protein-dye binding. Anal. Biochem. 72:248-254.

Chasan, R. 1994. Making sense (suppression) of viral RNA-mediated resistance. Plant Cell 6:1329-1331.

Courtney-Gutterson, N., E. Firoozabady, C. Lemieux, J. Nicholas, A. Morgan, K. Robinson, A. Otten, and M. Akerboom. 1993. Production of genetically engineered color-modified chrysanthemum plants carrying a homologous chalcone synthase gene and their field performance. Acta Hort. 336:57-62.

Daub, M.E., A.E. Jenns, L.A. Urban, and S.C. Brintle. 1994. Transformation frequency and foreign gene expression in burley and flue-cured cultivars of tobacco. Tob. Sci. 38:51-54.

Daub, M.E., R.K. Jones, and J.W. Moyer. 1997. Biotechnological approaches for virus resistance in floral crops, p. 335-351. In: R.L. Geneve, J.E. Preece, and S.A. Merkle (eds.). Biotechnology of ornamental plants. CAB Intl., Wallingford.

Dons, J.J.M., C. Mollema, W.J. Stickema, and B. Visser. 1991. Routes to the development of disease resistant ornamentals, p. 387-417. In: J. Harding, F. Singh, and J.N.M. Mol (eds.). Genetics and breeding of ornamental species. Kluwer Academic Publ., Dordrecht.

Earle, E.D. and R.W. Langhans. 1974. Propagation of Chrysanthemum in vitro I. Multiple plantlets from shoot tips and the establishment of tissue cultures. J. Amer. Soc. Hort. Sci. 99: 128-132. 
Fang, G., S. Hammer, and R. Grumet. 1992. A quick and inexpensive method for removing polysaccharides from plant genomic DNA. Bio/ Technology 13:52-55.

Fujii, Y. and K. Shimizu. 1990. Regeneration of plants from achenes and petals of Chrysanthemum coccineum. Plant Cell Rpt. 8:625-627.

Jefferson, R.A. 1987. Assaying chimeric genes in plants: the GUS gene fusion system. Plant Mol. Biol. Rpt. 5:387 405.

Kaul, V., R.M. Miller, J.F. Hutchinson, and D. Richards. 1990. Shoot regeneration from stem and leaf explants of Dendranthema grandiflora Tzvelev (syn. Chrysanthemum morifolium Ramat.). Plant Cell Tiss. Org. Cult. 21:21-30.

Ledger, S.E., S.C. Deroles, and N.K. Given. 1991. Regeneration and Agrobacterium-mediated transformation of chrysanthemum. Plant Cell Rpt. 10:195-199.

Lowe, J.M., M.R. Davey, J.B. Power, and K.S. Blundy. 1993. A study of some factors affecting transformation and plant regeneration of Dendranthema grandiflora Tzvelev (syn. Chrysanthemum morifolium Ramat.). Plant Cell Tiss. Org. Cult. 33:171-180.

McGarvey, P. and J.M. Kaper. 1991. A simple and rapid method for screening transgenic plants using PCR. Bio/Technology 11:428-432.

Malure, R.S., G. Barclay, J.B. Power, and M.R. Davey. 1991. The production of novel plants from florets of Chrysanthemum morifolium using tissue culture I. Shoot regeneration from ray florets and somaclonal variation exhibited by regenerated plants. J. Plant Physiol. 139:8-13.

May, R.A. and R.N. Trigiano. 1991. Somatic embryogenesis and plant regeneration from leaves of Dendranthema grandiflora. J. Amer. Soc. Hort. Sci. 116:366-371.

Murashige, T. and F. Skoog. 1962. A revised medium for rapid growth and bioassays with tobacco tissue cultures. Physiol. Plant. 15:473-497. Pavingerova, D., J. Dostal, R. Biskova, and V. Benetka. 1994. Somatic embryogenesis and Agrobacterium-mediated transformation of chrysanthemum. Plant Sci. 97:95-101.

Potrykus, I. 1990. Gene transfer to plants: Assessment and perspectives. Physiol. Plant. 79:125-134.

Renou, J.P., P. Briochard, and R. Jalouzot. 1993. Recovery of transgenic chrysanthemum (Dendranthema grandiflora Tzvelev) after hygromycin resistance selection. Plant Sci. 89:185-197.

Robinson, K.E.P. and E. Firoozabady. 1993. Transformation of floriculture crops. Sci. Hort. 55:83-99.

Sauvadet, M.A., P. Brochard, and J. Boccon-Gibco. 1990. A protoplastto-plant system in chrysanthemum: Differential responses among several commercial clones. Plant Cell Rpt. 8:692-695.

Seiichi, F, J. de Jong, and W. Rademaker. 1995. Efficient genetic transformation of chrysanthemum (Dendranthema grandiflora (Ramat.) Kitamura) using stem segments. Breed. Sci. 45:179-184.

Sherman, J.M., J.W. Moyer, and M.E. Daub. 1996. Genetically engineered resistance to tomato spotted wilt virus in chrysanthemum, Dendranthema grandiflora: A model system for virus protection in ornamental crops. Acta Hort. 431:432-441.

Urban, L.A., J.M. Sherman, J.W. Moyer, and M.E. Daub. 1994. High frequency shoot regeneration and Agrobacterium-mediated transformation of chrysanthemum (Dendranthema grandiflora). Plant Sci. 98:69-79.

Yepes, L.M., V. Mittak, S. Pang, C. Gonsalves, J.L. Slightom, and D. Gonsalves. 1995. Biolistic transformation of chrysanthemum with the nucleocapsid gene of tomato spotted wilt virus. Plant Cell Rpt. 14:694 698. 